\title{
A New Series of Pyrimidine-Containing Linear Molecules: Their Elegant Crystal Structures and Intriguing Photophysical Properties
}

\author{
Ken-Tsung Wong,* Fu-Chuan Fang, Yi-Ming Cheng, Pi-Tai Chou,* Gene-Hsiang Lee, and \\ Yu Wang \\ Department of Chemistry, National Taiwan University, Taipei 106, Taiwan \\ kenwong@ntu.edu.tw; chop@ntu.edu.tw \\ Received June 28, 2004
}

\begin{abstract}
A new series of aza-substituted analogues 3-5 based on the 1,4-bis(phenylethynyl)benzene moiety have been synthesized by the selective Pd-catalyzed Sonogashira coupling reaction from 5-bromo2-iodopyrimidine (1). In these linear molecules, the dipolar pyrimidine moiety is introduced as a probe to investigate factors that control the intermolecular interactions over the crystal engineering. The results reveal that the manner of packing changes both dipolar interactions between linear pyrimidine-containing molecules and transition moments simultaneously, resulting in remarkably different photophysical properties. Due to their versatile dipole-dipole and face-to-face $\pi-\pi$ interactions in a crystal motif, further applications on the design of ordered crystalline materials for the field effect transistors are promising.
\end{abstract}

\section{Introduction}

Linear arylethynyl molecules with extended $\pi$-conjugation are of considerable research interest due to their potential application in optoelectronics, ${ }^{1}$ sensors, ${ }^{2}$ and molecular devices. ${ }^{3}$ Significant progress has been made to develop functional materials with ethynyl skeleton via modifying the primary structure of the conjugated system. ${ }^{4}$ For example, incorporating electroactive heteroarenes such as thiophene into the backbone gives rise to new materials with interesting properties of electron conductivity and transport. ${ }^{5}$ Moreover, linear oligomers bearing $2,2^{\prime}$-bipyridine, ${ }^{6}$ terpyridine,${ }^{7}$ or 1,10 -phenanthroline ${ }^{8}$ as

(1) (a) Bunz, U. H. F. Chem. Rev. 2000, 100, 1605. (b) Kraft, A.; Grimsdale, A. C.; Holmes, A. B. Angew. Chem., Int. Ed. 1998, 37, 402 (c) Weder, C.; Sarwa, C.; Bastiaansen, C.; Smith P. Adv. Mater. 1997, 9, 1035. (d) Montali, A.; Bastiaansen, C.; Smith P.; Eeder, C. Nature 1998, 392, 261. (e) Weder, C.; Sarwa, C.; Montali, A.; Bastiaansen, C.; Smith P. Science 1998, 279, 835.

(2) (a) McQuade, D. T.; Pullen, A. E.; Swager, T. M. Chem. Rev. 2000 100, 2537. (b) Wang, J.; Wand, D.; Miller, E. K.; Moses, D.; Bazan, G. C.; Heeger, A. J. Macromolecules 2000, 33, 5153.

(3) (a) Petty, M. C.; Bryce, M. R.; Bloor, D. Introduction to Molecular Electronics; Edward Arnold: London, UK, 1995. (b) Tour, J. M. Acc. Chem. Res. 2000, 33, 791.

(4) For metal hybrid alkynes see: Wong, K.-T.; Lehn, J.-M.; Peng, S.-M.; Lee, G.-H. Chem. Commun. 2000, 2259 and references therein. Photoactive switch: (a) Marsella, M. J.; Wang, Z.-Q.; Mitchell, R. H. Org. Lett. 2000, 2, 2979. Matsuda, K.; Irie, M. J. Am. Chem. Soc. 2000, 122, 7195. (b) Fernandez-Acebes, A.; Lehn, J.-M. Chem. Eur. J. 1999, 5,3285 .

(5) Tour, J. M. Chem. Rev. 1996, 96, 537.

(6) (a) Birckner, E.; Grummt, U.-W.; Göller, A. H.; Pautzsch, T.; Egbe, D. A. M.; Al-Higari, M.; Klemm, E. J. Phys. Chem. A 2001, 105 , 10307. (b) Grummt, U.-W.; Birckner, E.; Klemm, E.; Egbe, D. A. M.; Heise, B. J. Phys. Org. Chem. 2000, 13, 112. (c) Ley, K. D.; Whittle, C. E.; Bartberger, M. D.; Schanze, K. S. J. Am. Chem. Soc. 1997, 119, 3423. (d) Ley, K. D.; Schanze, K. S. Coordi. Chem. Rev. 1998, 171, 287. (e) Walters, K. A.; Ley, K. D.; Schanze, K. S. Langmuir 1999, 15, 5676. (f) Khatyr, A.; Ziessel, R. J. Org. Chem. 2000, 65, 7814.

(7) Khatyr, A.; Ziessel, R. J. Org. Chem. 2000, 65, 3126. a functional moiety have been developed. The resulting materials may render useful sensing properties for proton or metal ions. More recently, a phenyl ring bearing both donor and acceptor groups has been introduced as the central skeleton for a molecular wire, leading to an intriguing negative differential resistance. ${ }^{9}$ For most optical applications based on arylethynyl materials, optimization of the emission efficiency is the major challenge. In concentrated thin films as well as in bulk solids, the emission intensities of the linear arylethynyl materials normally tend to decrease, along with a bathochromic shift and broadening of the electronic absorption and/or fluorescence spectra, the phenomena of which are primarily attributed to the molecular aggregation. ${ }^{10}$ Thus, materials functionalized by bulky substituents to suppress the self-quenching effects via hindering or minimizing the cofacial aggregations usually exhibit highly efficient fluorescence in the solid state. ${ }^{11}$ Furthermore, recent studies on the conformation-dependent photophysical properties have revealed that the twisting angle for the aryl versus the linear enthynyl groups is crucial to account for the spectral variations, ${ }^{12}$ while the relative orientation of the planar aromatic system along the

(8) (a) Joshi, H. S.; Jamshidi, R.; Tor, Y. Angew. Chem., Int. Ed. 1999, 38, 2722. (b) Bousquet, S. J. P.; Bruce, D. W. J. Mater. Chem. 2001, 11, 1769. (c) Tzalis, D.; Tor, Y. Tetrahedron Lett. 1996, 37, 8293 (d) Tzalis, D.; Tor, Y. Tetrahedron Lett. 1995, 36, 6017.

(9) Chen, J.; Reed, M. A.; Rawlett, A. M.; Tour, J. M. Science 1999, 286,1550 .

(10) (a) Tan, C.; Pinto, M. R.; Schanze, K. S. Chem. Commun. 2002, 446. (b) McQuade, D. T.; Kim, J.; Swager, T. M. J. Am. Chem. Soc. 2000, 122, 5885. (c) Turro, N. J. Modern Molecular Photochemistry; University Science Books: Sausalito, CA, 1991. (d) Lakowicz J. R. Principle of Fluorescence Spectroscopy, 2nd ed.; Kluwer Academic/ Plenum Publishers: New York, 1999.

(11) (a) Williams, V. E.; Swager, T. M. Macromolecules 2000, 33, 4069. (b) Yang, J.-S.; Swager, T. M. J. Am. Chem. Soc. 1998, 120, 11864 .

10.1021/jo048914h CCC: $\$ 27.50$ @ 2004 American Chemical Society Published on Web 10/15/2004 
molecular axis plays an important role in modifying the conductivity of a molecular wire. ${ }^{13}$ Along this line, probing the factors that affect the conformational changes as well as the formation and characteristics of molecular aggregation becomes fundamentally important. In one aspect, the nature of interchromophore interactions can be attained via X-ray structural analyses in combination with the photophysical properties in the crystalline form. ${ }^{14}$ Information provided from these investigations may gain deep insights into the relationship between molecular structure and physical properties. In another aspect, to engineer efficient and applicable molecular devices, control of the interbackbone interactions is an important issue. Different intermolecular interactions such as hydrogen bonding, $\pi-\pi$ stacking, van der Waals, and dipole-dipole, can be applied to fine-tune the molecular alignments. On this basis, many exquisite works have been reported based on self-assembly techniques, leading to great successes in the development of polymerbased organic electronics. ${ }^{15}$

Aimed at the design and synthesis of efficient materials for field effect transistors (FETs), we envisage taking advantage of the moderately strong dipole-dipole interactions as a crystal-engineering motif to control the molecular crystal packing. For this purpose, it is reasonable to select pyrimidine as a candidate because the dipolar interactions between pyrimidine-containing molecules have been widely applied for the preparation of liquid crystalline materials. ${ }^{16}$ To further explore this intriguing type of intermolecular interaction in crystal engineering, we have synthesized a series of azasubstituted analogues of 1,4-bis(phenylethynyl)benzene. Their elegant crystal structures along with interesting photophysical properties in the crystalline forms are reported in this contribution.

\section{Results and Discussion}

2.1. Synthesis. The high chemoselectivity of 5-bromo2-iodopyrimidine (1) toward Pd-catalyzed coupling reactions provides an effective synthetic strategy for sequen-

(12) (a) Schmieder, K.; Levitus, M.; Dang, H.; Garcia-Garibay, M. A. J. Phys. Chem. 2002, 106, 1551. (b) Beeby, A.; Findlay, K.; Low. P. J.; Marder, T. B. J. Am. Chem. Soc. 2002, 124, 8280. (c) Levtius, M.; Zepeda, G.; Dang, H.; Godinez, C.; Khuong, T.-A. V.; Schmieder, K. Garcia-Garibay, M. A. J. Org. Chem. 2001, 66, 3188. (d) Levtius, M.; Schmieder, K.; Ricks, H.; Shimizu, K. D.; Bunz, U. H. F.; GarciaGaribay, M. A. J. Am. Chem. Soc. 2001, 123, 4259. (e) McFarland, S. A.; Finney, N. S. J. Am. Chem. Soc. 2001, 123, 1260. (f) McFarland, S. A.; Finney, N. S. J. Am. Chem. Soc. 2002, 124, 1178.

(13) Donhauser, Z. J.; Mantooth, B. A.; Kelly, K. F.; Bumm, L. A.; Monnell, J. D.; Stapleton, J. J.; Price, D. W., Jr.; Rawlett, A. M.; Allara, D. L.; Tour, J. M.; Weiss, P. S. Science 2001, $292,2303$.

(14) (a) Lewis, F. D.; Yang, J.-S.; Stern, C. L. J. Am. Chem. Soc. 1996, 118, 2772. (b) Lewis, F. D.; Yang, J.-S. J. Phys. Chem. B 1997, 101, 1775. (c) Singh, A. K.; Krishna, T. S. R. J. Phys. Chem. A 1997 101, 3066. (d) Brinjman, M.; Gadret, G.; Muccini, M.; Taliani, C.; Masciochi, N.; Sironi, A. J. Am. Chem. Soc. 2000, 122, 5147. (e) Koren, A. B.; Curtis, M. D.; Francis, A. H.; Kampf, J. W. J. Am. Chem. Soc. 2003, $125,5040$.

(15) (a) Tracz, A.; Jeszka, J. K.; Watson, M. D.; Pisula, W.; Mullen, K.; Pakula, T. J. Am. Chem. Soc. 2003, 125, 1682. (b) Katz, H. E.; Bao, Z.; Gilat, S. L. Acc. Chem. Res. 2001, 34, 359.

(16) (a) Sharma, S.; Lacey, D.; Wilson, P. Liq. Cryst. 2003, 30, 451. (b) Lin, Y.-C.; Lai, C. K.; Chang, Y.-C.; Liu, K.-T. Liq. Cryst. 2002, 29, 237. (c) Vizitiu, D.; Lazar, C.; Halden, B. J.; Lemieux, R. P. J. Am. Chem. Soc. 1999, 121, 8229. (d) Mueller, I.; Hemmerling, W.; Wingen, R. Ferroelectrics 1988, 85, 393. (e) Gupta, S.; Mandal, P.; Paul, S.; De Wit, M.; Goubitz, K.; Schenk, H. Mol. Cryst. Liq. Cryst. 1991, 195, 149. (f) Suenaga, H.; Maeda, S.; Iijima, T.; Kobayashi, S. Mol. Cryst. Liq. Cryst. 1987, 144, 191.
SCHEME 1. The Synthesis of Pyrimidine-Containing Linear Molecules

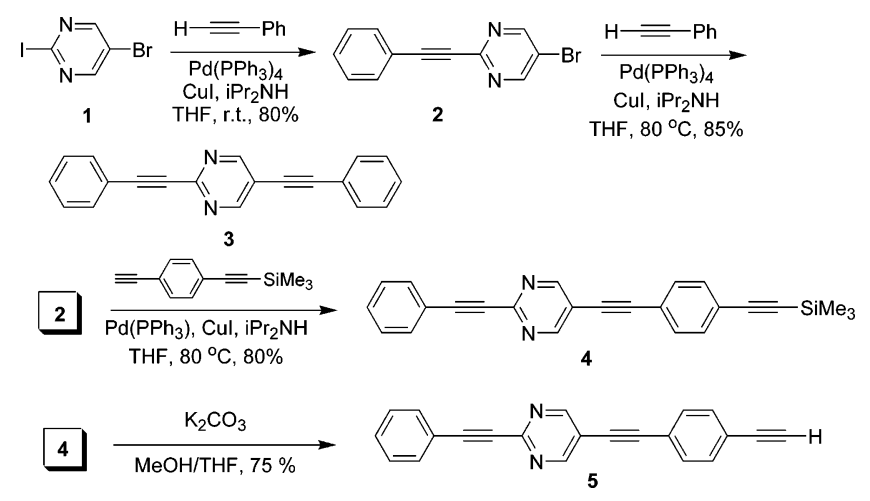

tially introducing different alkynes at 2 and 5 positions of pyrimidine. ${ }^{17}$ The control on the different arrangements of the dipolar orientation of pyrimidine along a well-defined conjugated system has previously been achieved in our laboratory. ${ }^{18}$ The synthesis of phenylethynylene-pyrimidine linear molecules by the Pdcatalyzed Sonogashira reaction starting from 5-bromo2-iodopyrimidine (1) is outlined in Scheme 1.

The selective Sonogashira coupling reaction of $\mathbf{1}$ on the iodo-substituted carbon with phenylacetylene was carried out under standard conditions with $\mathrm{Pd}\left(\mathrm{PPh}_{3}\right)_{4}$ as the catalyst, $\mathrm{CuI}$ as the cocatalyst, and diisopropylamine as the base in THF at room temperature. 5-Bromo-2phenylethynylpyrimidine (2) was obtained in $80 \%$ yield after purification by chromatography. Further, $\mathbf{2}$ is coupled with another equivalent of phenylacetylene at $80{ }^{\circ} \mathrm{C}$ to furnish 2,5-bis(phenylethynyl)pyrimidine (3) in $85 \%$ yield. Compound $\mathbf{3}$ can also be efficiently prepared in one pot from 1 with the addition of an excess amount of phenylacetylene at $80^{\circ} \mathrm{C}$ by using the same catalytic system. The isolated yields for both stepwise and onepot syntheses are comparable. Introducing a new conjugated skeleton on the phenyl group may further increase the backbone conjugation length of $\mathbf{3}$. Accordingly, treatment of $\mathbf{2}$ with 4-(trimethylsilylethynyl)phenylacetylene in the presence of $\mathrm{Pd}$ catalyst and cocatalyst $(\mathrm{CuI})$ at 80 ${ }^{\circ} \mathrm{C}$ afforded dissymmetric linear molecule 4 in $80 \%$ isolated yield. The removal of the alkyne-protecting group (trimethylsilyl group, TMS) was provided with $\mathrm{K}_{2} \mathrm{CO}_{3}$ in $\mathrm{MeOH} / \mathrm{THF}$ to afford $\mathbf{5}$ in $75 \%$ yield. Further extension of the conjugation length is achievable by reacting 5 with 1 or other halogenated arenes.

2.2. X-ray Crystal Structures. A single crystal of $\mathbf{3}$ was obtained by carefully layering the THF solution containing 3 with $n$-hexane at ambient temperature. A clear identification of the exact position of nitrogen atoms in the molecule is not possible due to the disordered arrangement of the nitrogen atoms in the molecular structure. The structure shown in Figure 1 is drawn with a 50\% probability of interexchanging nitrogen atoms $[\mathrm{N}(1), \mathrm{N}(1 \mathrm{~B})]$ and carbons $[\mathrm{C}(1 \mathrm{~A}), \mathrm{C}(1 \mathrm{C})]$. Obviously, the aromatic rings of $\mathbf{3}$ are nearly coplanar with a dihedral angle of $0.43^{\circ}$ between the phenylene ring and the

(17) (a) Shibata, T.; Yonekubo, S.; Soai, K. Angew. Chem., Int. Ed. 1999, 38, 659. (b) Goodby, J. W.; Hird, M. H.; Lewis, R. A.; Toyne, K. J. Chem. Commun. 1996, 2719.

(18) (a) Wong, K.-T.; Lu, Y.-R.; Liao, Y.-L. Tetrahedron Lett. 2001 42, 6341. (b) Wong, K.-T.; Hsu, C. C. Org. Lett. 2001, 3, 173. 


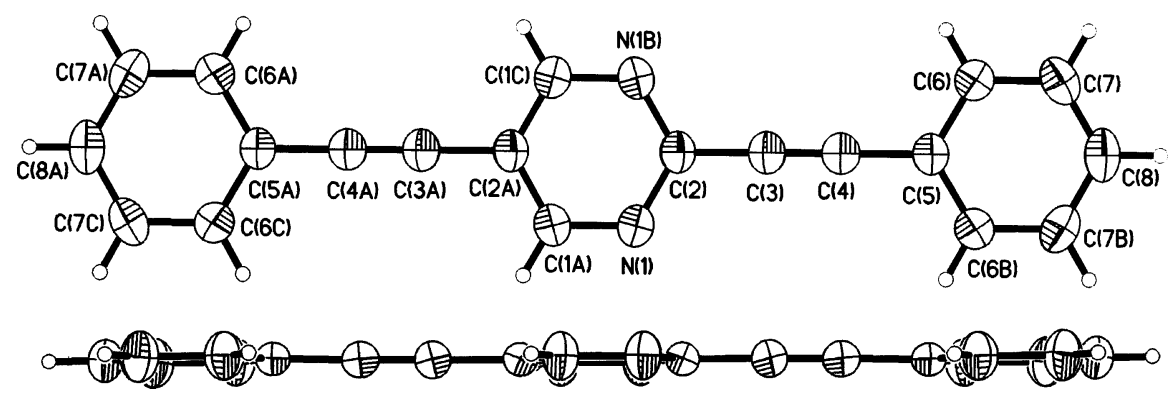

FIGURE 1. The thermal ellipsoid plot of the crystal structure of $\mathbf{3}$ at the $50 \%$ probability level.

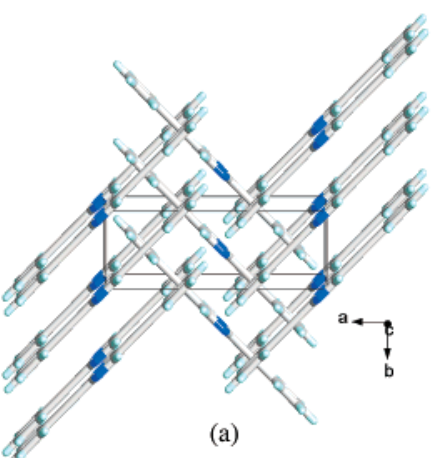

(a)

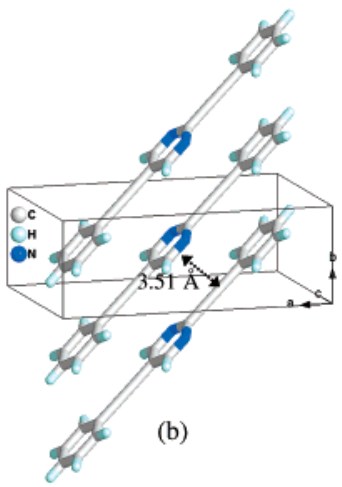

FIGURE 2. (a) The crystal packing diagram of $\mathbf{3}$ as seen along the $c$-axis. (b) The presentation of stepped plane-to-plane interactions within the crystal packing.

pyrimidine ring, and the molecule is almost linear with bond angles between triple bonds and adjacent atoms of $179.5^{\circ}(\mathrm{C}(2)-\mathrm{C}(3)-\mathrm{C}(4))$ and $179.8^{\circ}(\mathrm{C}(3)-\mathrm{C}(4)-\mathrm{C}(5))$. The structure resembles that of 1,4-bis(phenylethynyl)benzene possessing a linear, coplanar structure in the solid state. ${ }^{19}$ However, as shown in Figure 2, the crystalpacking diagram of $\mathbf{3}$ is completely different from the $S$-shaped crystal packing behavior of 1,4-bis(phenylethynyl)benzene. The crystal packing of $\mathbf{3}$ is comprised of two translationally nonequivalent infinite $\pi$-stacks, which are perpendicular to each other, resulting in a cross-herringbone-like packing pattern as viewed from the projection along the $c$ axis (Figure 2a). Molecules within a given $\pi$-stack are tilted by ca. $46^{\circ}$ with respect to the stacking axis ( $b$-axis), and are stepped relative to one another along the long axis of conjugation, rendering a zigzagstaircase structure that allows the center of one aromatic ring placed on top of the $\mathrm{C}-\mathrm{C}$ triple bond of the next molecule (Figure 2b). The perpendicular intermolecular distance between the $\mathrm{C}(4)$ and the plane of the central pyrimidine ring of the neighboring molecule is estimated to be $3.51 \AA$, suggesting the existence of $\pi-\pi$ interactions. Although an unambiguous X-ray identification of the position of nitrogen atoms is difficult at this stage, we speculate that the moderate dipolar and, in part, the clear $\pi-\pi$ interactions between the neighboring molecules play an important role on guiding compound $\mathbf{3}$ to an extremely ordered crystal packing.

To further support the above viewpoint as well as to probe the effects of possible intermolecular dipolar interactions on the crystal packing, unsymmetric molecules

(19) Li, H.; Powell, D. R.; Firman, T. K.; West, R. Macromolecules 1998, 31, 1093 .

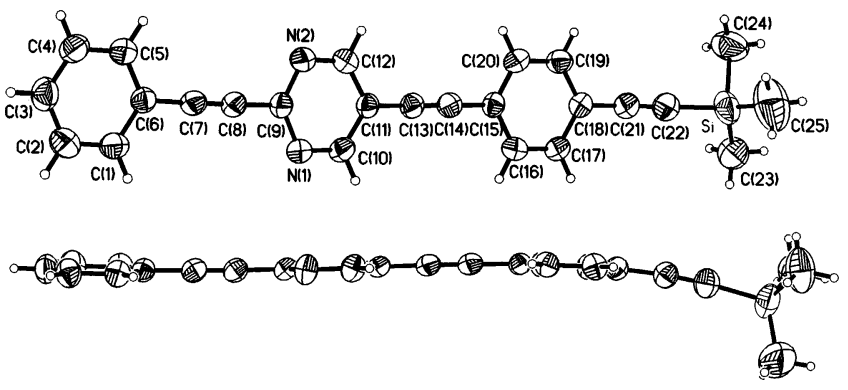

FIGURE 3. The thermal ellipsoid plot of the molecular structure of $\mathbf{4}$ at the $50 \%$ probability level.

$\mathbf{4}$ and $\mathbf{5}$ were synthesized. Single crystals of $\mathbf{4}$ and $\mathbf{5}$ suitable for X-ray analyses were obtained from layering the THF solution of $\mathbf{4}$ and $\mathbf{5}$ with $\mathrm{MeOH}$ at ambient temperature. For crystal data of $\mathbf{4}$ and $\mathbf{5}$ please see the Supporting Information for details. The crystal structure of $\mathbf{4}$ on the main conjugated backbone resembles that of 3 (Figure 3) except for the coplanarity among the aryl rings. The phenyl ring attached to trimethylsilylethynyl group is slightly twisted from the molecular plane of the pyrimidine ring with a dihedral angle of $4.30^{\circ}$, whereas the dihedral angle between the terminal phenylene ring and the pyrimidine ring is calculated to be $4.25^{\circ}$. The $\mathrm{C} \equiv \mathrm{C}-\mathrm{C}(\mathrm{Ar})$ bond angle is as linear as $178.9^{\circ}$, except for the terminal trimethylsiylethynyl group that slightly bends away from the linear backbone. The $\mathrm{Si}-\mathrm{C}(22)-\mathrm{C}(21)$ and $\mathrm{C}(22)-\mathrm{C}(21)-\mathrm{C}(18)$ bond angles are estimated to be $175.1^{\circ}$ and $176.1^{\circ}$, respectively. This bending structure, which may be ascribed to the longer $\mathrm{C}-\mathrm{Si}$ bond and the crystal packing forces, is occasionally observed in the silicon-containing alkynyl compounds. ${ }^{20}$ Apparently, the steric bulkiness of the TMS group has pronounced effects on the crystal packing. The conjugated backbones of neighboring molecules within the chain are aligned in a plane-to-plane but antiparallel manner to mitigate the steric interactions raised from the bulky TMS group in 4.

As shown in Figure 4a there are two pairs of step-type molecular packing within the chain structure. The pair of molecules $\mathrm{B}$ and $\mathrm{C}$ has a longer plane-to-plane contact, in which the aromatic rings are located over the others of the next molecule with a closest $\mathrm{C}(8)-\mathrm{C}\left(13^{\prime}\right)$ interatomic distance of $3.64 \AA$, indicating a weak and possibly negligible $\pi-\pi$ stacking effect. Alternatively, the dipoledipole interaction between the neighboring pyrimidine

(20) (a) Anthony, J. E.; Eaton, D. L.; Parkin, S. R. Org. Lett. 2002 4, 15. (b) Anthony, J. E.; Brooks, J. S.; Eaton, D. L.; Parkin, S. R. J. Am. Chem. Soc. 2001, 123, 9482.

8040 J. Org. Chem., Vol. 69, No. 23, 2004 

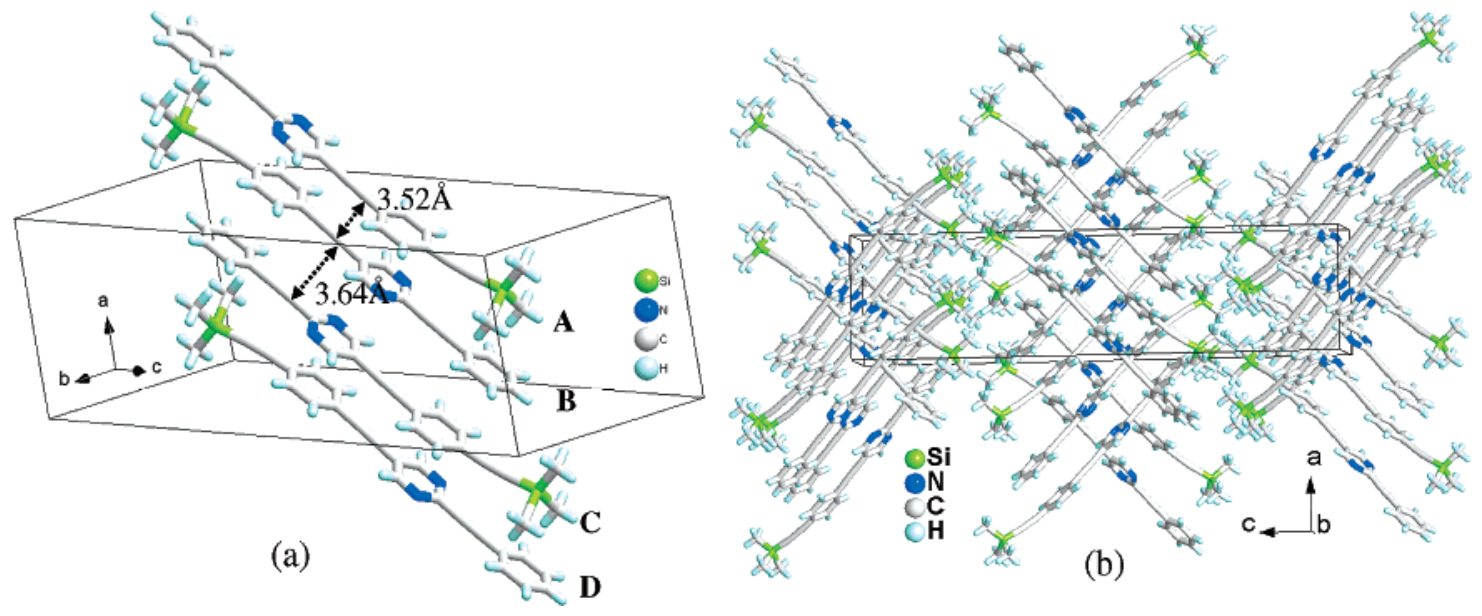

FIGURE 4. (a) The presentation of different plane-to-plane interactions within the crystal packing of 4. (b) The crystal packing diagram of molecule 4 .

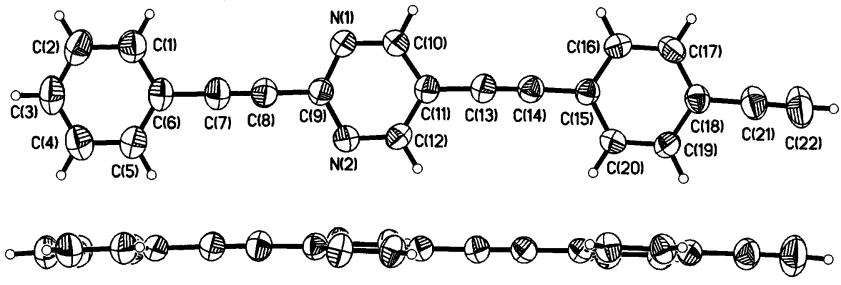

FIGURE 5. The thermal ellipsoid plot of the molecular structure of $\mathbf{5}$ at the $50 \%$ probability level.

rings of molecule $\mathrm{B}$ and $\mathrm{C}$ is plausibly the dominant factor that dictates the molecular alignment. For molecules $\mathrm{A}$ and $\mathrm{B}$, the plane-to-plane interactions are only restricted to the pyrimidine ring and the phenyl ring attached to a trimethylsilylethynyl group. The interplanar $\mathrm{C}(13)-\mathrm{C}\left(14^{\prime}\right)$ distance is estimated to be $3.52 \AA$, suggesting moderate face-to-face intermolecular interactions among the aromatic systems in the crystalline form. A similar packing pattern is also resolved in the pair of molecules $\mathrm{C}$ and $\mathrm{D}$. Thus, the entire chain structure is comprised of these two alternative pairs of molecules. The dipolar interactions and face-to-face $\pi-\pi$ stacking efficiently guide the crystal packing of 4 , leading to a slightly tilted cross-herringbone-type or T-shaped/parquettype packing fashion (Figure $4 \mathrm{~b}$ ) analogous to that of $\mathbf{3}$. This observation may support our speculation of possible dipole-dipole interactions in the crystal packing of $\mathbf{3}$.

The crystal structure of $\mathbf{5}$ is shown in Figure 5. The phenyl ring attached to an ethynyl group slightly bends from the linear molecular backbone. The $\mathrm{C}(13)-\mathrm{C}(14)-\mathrm{C}(15)$ bond angle is estimated to be $177.9^{\circ}$, being comparable to $\mathrm{C} \equiv \mathrm{C}-\mathrm{C}(\mathrm{Ar})$ with an average bond angle of $178.7^{\circ}$. In comparison to that of crystal $\mathbf{3}$, the linear 1-D chain with a less coplanar configuration for aromatic rings becomes obvious. The phenyl ring attached to an ethynyl group is twisted from the molecular plane of the pyrimidine ring with a dihedral angle of $7.92^{\circ}$, whereas the dihedral angle between the terminal phenylene ring and the pyrimidine ring is calculated to be $5.80^{\circ}$. The crystal packing of molecule $\mathbf{5}$ is significantly different from those of $\mathbf{3}$ and $\mathbf{4}$, which periodically pack in piles on top of each other as viewed from the projection along the $a$ axis (Figure 6).

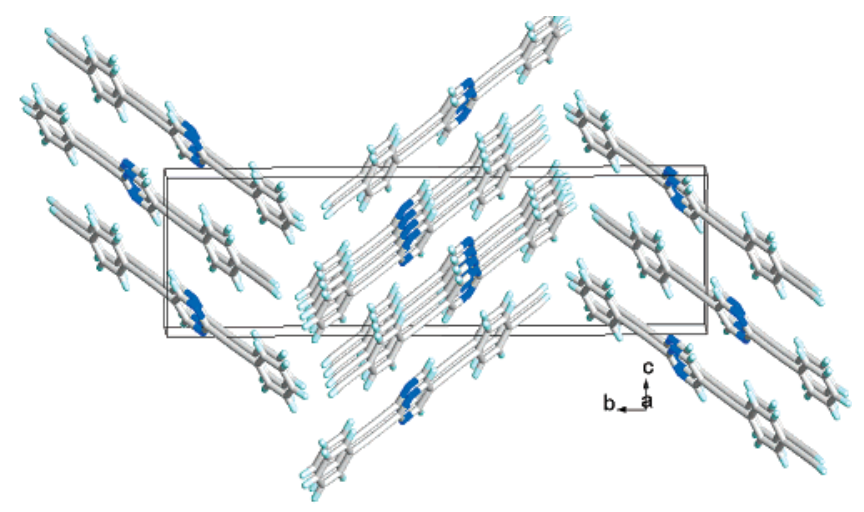

FIGURE 6. The crystal packing of molecule $\mathbf{5}$.

The molecular stacks are arranged in such a way that constitutes a ribbonlike structure along the $c$ axis. To efficiently increase the attraction, hence the stabilization, the neighboring molecular stacks within each individual ribbon are arranged in an antiparallel manner. The two neighboring ribbons are then tilted with respect to each other, leading to a herringbone-like packing pattern. Upon close inspection of the crystal structure from various viewing angles, we found that, within the individual band, there exist two types of short $\mathrm{N}-\mathrm{H}$ distances between neighboring molecules, indicating the possible existence of weak, non-hydrogen-bonding interactions.

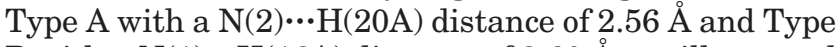
B with a $\mathrm{N}(1) \cdots \mathrm{H}(16 \mathrm{~A})$ distance of $2.60 \AA$ are illustrated in Figure $7 \mathrm{a}$. These two short $\mathrm{N} \cdots \mathrm{H}$ interactions result in the formation of an infinite wrinkled sheet (as shown in the side view of Figure 7b).

In addition, the terminal ethynyl hydrogen $\mathrm{H}(3 \mathrm{~A})$ is very close to the $\mathrm{H}\left(22 \mathrm{~A}^{\prime}\right)$ of the adjacent molecule with a $\mathrm{H}(3 \mathrm{~A})-\mathrm{H}\left(22 \mathrm{~A}^{\prime}\right)$ distance estimated to be $3.02 \AA$. This nearly perpendicular head-to-tail arrangement of the adjacent bands leads to a zigzag packing feature shown in Figure 8a. Theoretically, the removal of the bulky TMS group from 4, giving compound 5, should effectively release the intermolecular steric interactions. Along this line, a closer plane-to-plane stack is expected for the crystal structure of $\mathbf{5}$. Upon careful inspection on the crystal packing of $\mathbf{5}$, two types of plane-to-plane contact 


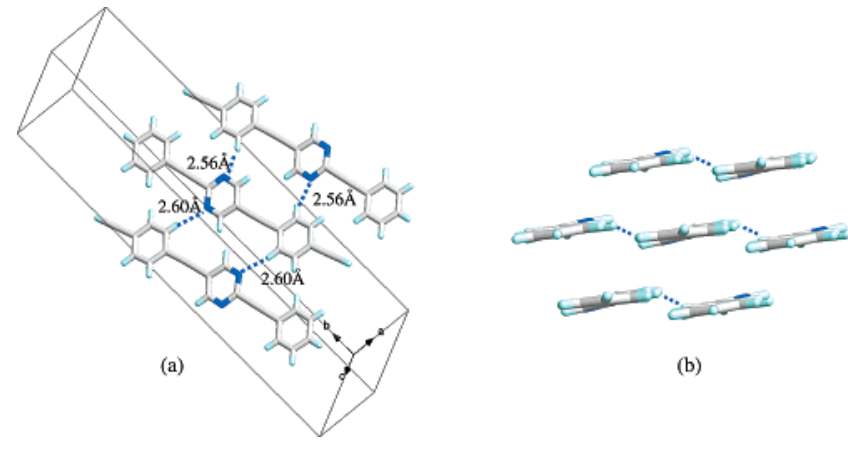

FIGURE 7. (a) The view of the crystal packing of $\mathbf{5}$ with two different short $\mathrm{N}-$ - $\mathrm{H}$ distances between neighboring molecules. (b) The side view of the wrinkled sheetlike structure.

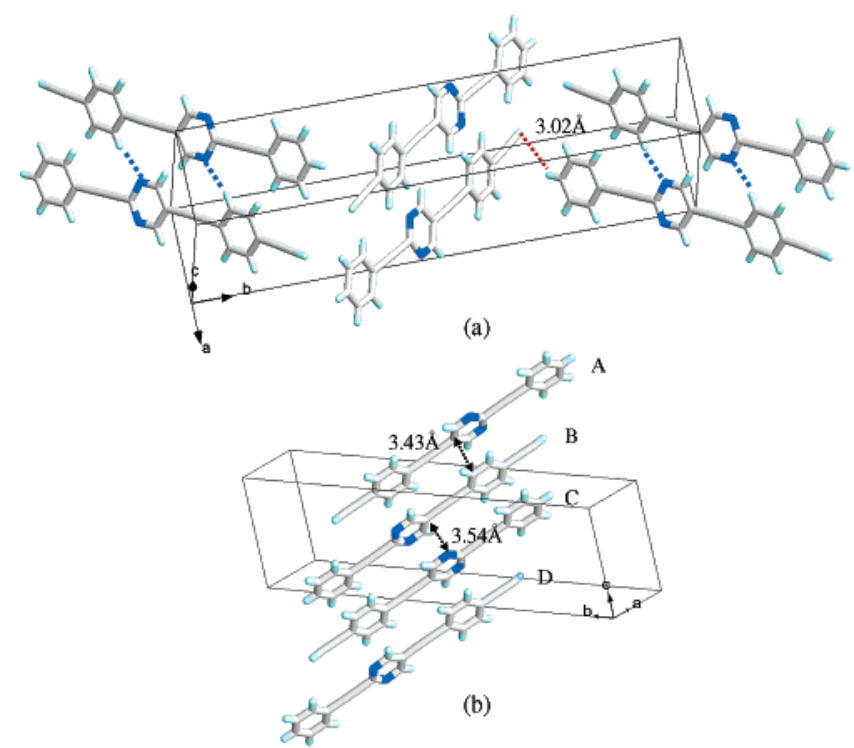

FIGURE 8. (a) The zigzag-type packing pattern of molecule 5. (b) The two different plane-to-plane interactions within the crystal of $\mathbf{5}$.

are identified, in which molecules $\mathrm{B}$ and $\mathrm{C}$ (Figure 8b) with different alignment of the dipolar orientation of pyrimidine are paired up as a group. Therefore, the three aromatic rings of the individual molecule within the pair (B and C) are superimposed with a closest $\mathrm{N}(2)-\mathrm{C}\left(11^{\prime}\right)$ interatomic distance of $3.54 \AA$. Another plane-to-plane contact between pairs also exists. In this case, the phenyl ring (molecule A) attached by a terminal ethynyl group is closer to the pryimidine ring (molecule $\mathrm{B}$ ) with a closest interatomic $\mathrm{C}(11)-\mathrm{C}\left(16^{\prime}\right)$ distance calculated to be 3.43 $\AA$, indicating the possibility of strong $\pi-\pi$ interactions in this region. Therefore, similar to the case found in molecule 4, the dipole-dipole interactions and significant plane-to-plane contact again play important roles on the crystal packing in $\mathbf{5}$.

2.3. Photophysical Properties. Figure 9 shows the absorption and emission spectra of $\mathbf{3 , 4}$, and $\mathbf{5}$ in roomtemperature cyclohexane. Detailed photophysical properties are listed in the Table 1 . For 3-5, the longest wavelength absorption peak with $\epsilon_{\max }$ values of $>10^{4} \mathrm{M}^{-1}$ $\mathrm{cm}^{-1}$ leads to the assignment of a characteristic $\pi-\pi^{*}$ transition unambiguously. For all three compounds studied, the corresponding room-temperature emission in cyclohexane is very weak $\left(\Phi_{\mathrm{f}} \ll 10^{-2}\right.$, see Table 1$)$. The

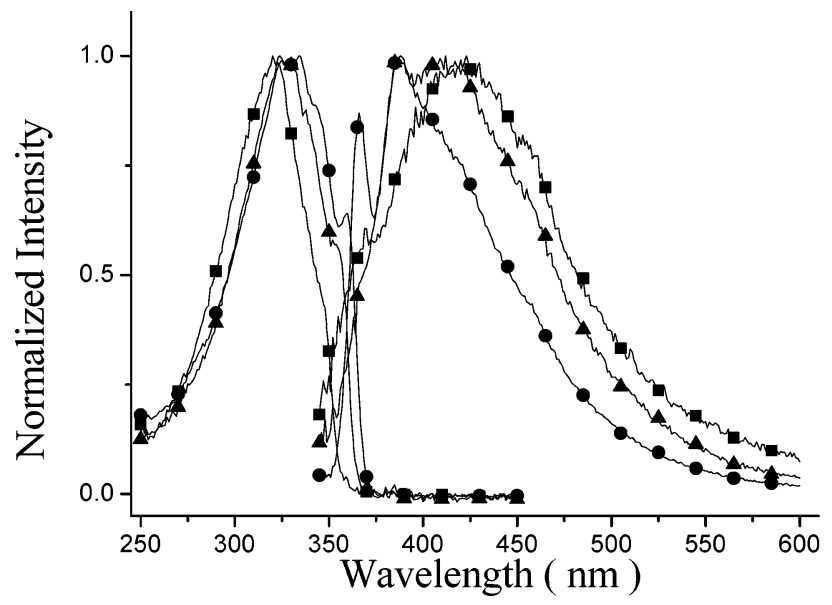

FIGURE 9. The absorption and emission spectra of 3 (ש), 4 $(\bullet)$, and $\mathbf{5}(\mathbf{\Lambda})$ in cyclohexane.

TABLE 1. The Photophysical Properties of 3, 4, and 5

\begin{tabular}{|c|c|c|c|c|c|c|c|}
\hline & $\lambda_{(\mathrm{mm})}(\mathrm{abs})^{a}$ & $\begin{array}{c}\epsilon_{\max }^{a} \\
\left(\mathrm{M}^{-1} \mathrm{~cm}^{-1}\right)\end{array}$ & $\lambda_{(\mathrm{max})}(\mathrm{em})^{a}$ & $\Phi_{\mathrm{f}}^{a}$ & $\lambda_{(\mathrm{mm})}$ & $\Phi_{\mathrm{f}}^{c}$ & $\begin{array}{l}\tau_{\mathrm{f}}^{b} \\
(\mathrm{~ns})\end{array}$ \\
\hline 3 & 320 & $4 \times 10^{4}$ & 425 & $9.0 \times 10^{-4}$ & 451 & 0.08 & 0.8 \\
\hline 4 & 335 & $8.2 \times 10^{4}$ & 390 & $8.5 \times 10^{-3}$ & 485 & 0.65 & 5.7 \\
\hline 5 & 325 & $5.3 \times 10^{4}$ & 415 & $1.5 \times 10^{-3}$ & 442 & 0.13 & 1.1 \\
\hline
\end{tabular}

luminescence intensity is linearly proportional to the increase of concentration, eliminating the emission associated with any high-order aggregation. The entire emission band originating from a common ground-state species is ascertained by the same fluorescence excitation spectra throughout the monitored wavelengths of $350-600 \mathrm{~nm}$. The excitation spectra, within experimental error, are also effectively identical with the absorption spectrum, indicating that the entire emission results from a common Franck-Condon excited state for $\mathbf{3} \mathbf{- 5}$.

For the case of $\mathbf{3}$, despite the slightly structural $\mathrm{S}_{0} \rightarrow \mathrm{S}_{1}\left(\pi, \pi^{*}\right)$ absorption band, the corresponding emission spectrum exhibits diffusive, broad spectral features with a peak wavelength at $425 \mathrm{~nm}$. The Stokes shift, defined as the difference in peak frequencies between absorption and emission bands, is as large as $\sim 7700 \mathrm{~cm}^{-1}$. As indicated by the similar Stokes shift being $\sim 8100 \mathrm{~cm}^{-1}$ in a much stronger polar solvent such as $\mathrm{CH}_{3} \mathrm{CN}$, such a large shift clearly does not originate from the solvent dipolar relaxation due to the large dipolar change of the solute (i.e. compound 3) upon excitation. Alternatively, the results, in combination with the low emission yield of $9.0 \times 10^{-4}$, can be more plausibly rationalized by the existence of various rotational isomers in the excited state. Unfortunately, the multiple degrees of rotational freedom in a large molecule such as $\mathbf{3}$ make quantitative analyses complicated. Although further relevant approaches are not pursued, quenching of the fluorescence dominated by the corresponding torsional motions is obvious, giving rise to extremely weak emission intensity. Similar dynamics of relaxation were applied to rationalize the broad, weak, and large Stokes shifted emission for compound $\mathbf{5}$ in solution. In contrast, the emission of $\mathbf{4}$ revealed a vibronic-like spectral feature that is a mirror image with respect to the corresponding absorption spectrum. The results, in combination with 


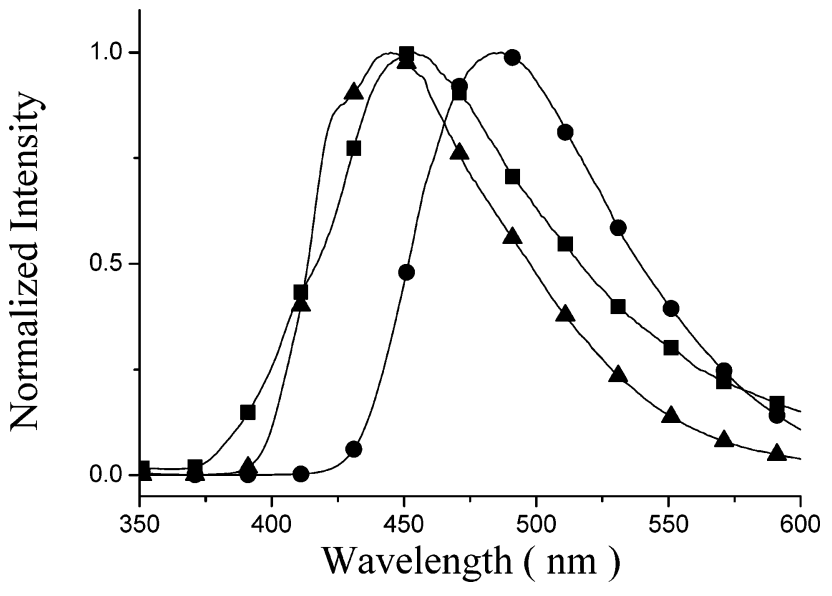

FIGURE 10. The emission spectra of $3(\boldsymbol{\square}), \mathbf{4}(\bullet)$, and $5(\Delta)$ in solid crystalline.

the highest quantum yield among three studied molecules, indicate that the introduction of a bulky TMS retards the internal rotational motions in $\mathbf{4}$ and hence, to a certain extent, diminishes the radiationless deactivation. However, the variation of electronic density of the conjugated chromophore perturbed by the TMS group ${ }^{21}$ may also play an important role on the higher photoluminescence efficiency for linear compound 4.

Drastic increase of the emission yield was observed for three studied compounds in a single crystal (Figure 10). The quantum efficiency was measured to be $0.08,0.65$, and 0.13 for $\mathbf{3}, \mathbf{4}$, and $\mathbf{5}$, respectively. The results correlate well with the time-dependent study, in which the lifetime is beyond the system response limit of $200 \mathrm{ps}$ for $\mathbf{3} \mathbf{- 5}$, while it was measured to be $0.8,5.7$, and $1.1 \mathrm{~ns}$ for $\mathbf{3}, \mathbf{4}$, and $\mathbf{5}$, respectively, in the solid crystalline form. In comparison to the solution phase, the increase of $\sim 2$ orders of magnitude of the emission efficiency in solid supports the rotational motions as the dominant deactivation process in solution. In the absence of largeamplitude motions the quenching of the fluorescence may be due to the $\mathrm{S}_{1} \rightarrow \mathrm{T}_{n}$ intersystem crossing. However, since phosphorescence is rather small for all three compounds in solid, the $\leq 0.65$ fluorescence yield cannot be solely attributed to the quenching by the intersystem crossing. Alternatively, it may be more plausible to propose that one radiationless channel is associated with the $\pi$-stacking effect in solid. This viewpoint can be supported by the highest quantum yield of 0.65 for 4 among 3-5 in solid, in which the slightly tilted crossherringbone-type or T-shaped/parquet-type packing fashion may provide less stacking force for the exciton formation. However, one cannot rule out that the specifically high quantum yield in $\mathbf{4}$, to a certain extent, is due to the different dipolar interaction in the antiparallel packing manner, which results in a larger transition moment than that of $\mathbf{3}$ and $\mathbf{5}$. Finally, for the case of $\mathbf{3}$, although dipole-dipole interactions in the crystal packing are strong (vide supra), the bathochromic shift $(\sim 25$ $\mathrm{nm}$ ) of the emission is rather small in comparison to that in cyclohexane. The results further support the viewpoint

(21) (a) Maeda, H.; Inoue, Y.; Ishida, H.; Mizuno, K. Chem. Lett. 2001, 1224. (b) Yamaguchi, S.; Xu, C.; Tamao, K. J. Am. Chem. Soc. 2003, 125, 13662 . that the large Stokes shifted emission for $\mathbf{3}$ in solution mainly results from the rotational electrochromism. Finally, it should be noted that in the quantum-yield measurement of solid, a film sample had to be prepared via either the spin coating or the vapor deposition method to obtain reliable data (see the Experimental Section). We have conducted an XRD analysis on a vacuum $(5 \times$ $10^{-6}$ Torr) deposited film of compound 4. Unfortunately, the diffraction pattern could not be resolved, indicating the formation of a complicated packing manner during the vacuum deposition. Despite the quantum yield measurement, other photophysical parameters were obtained in solid crystalline forms. Thus, the correlation between solid-state quantum yield and crystal structure may only be qualitative.

\section{Conclusion}

In conclusion, an efficient synthetic route to prepare a new series of aza-substituted analogues $\mathbf{3}-\mathbf{5}$ based on the 1,4-bis(phenylethynyl)benzene moiety has been established. The pyrimidine moiety is incorporated into these linear molecules for probing the possibility of dipolar interactions that can control the crystal packing. Comprehensive investigations on the crystal structures of these linear molecules have revealed that the dipoledipole interactions between proximal pyrimidine moieties as well as plane-to-plane contact between adjacent aryl rings play key roles in determining the crystal packing. In low viscous solution, various degrees of rotational freedom in $\mathbf{3}$ and $\mathbf{5}$ result in a large red-shifted emission with rather low yields. Anchoring a terminal TMS group drastically diminishes the rotational deactivation processes and the emission behaves as normal Stokes shifts. In a single crystal, factors such as steric hindrance, conjugation, etc. fine-tune the intermolecular interactions and hence the corresponding crystal engineering. The manner of packing changes both dipolar interactions between linear pyrimidine-containing molecules and transition moments simultaneously, resulting in substantially different photophysical properties. Information provided from these investigations, especially their unusually strong dipole-dipole interactions in a crystal motif, may shed more light on the nature and molecular design of materials for the highly efficient field effect transistor (FET). Focus on 3-5 in the application of EET is currently in progress.

\section{Experimental Section}

4.1. General Experimental Details. All reactions were performed under argon and were magnetically stirred. Solvents were distilled from appropriate drying agent prior to use: THF from sodium and benzophenone, diisopropylamine from $\mathrm{CaH}_{2}$. Commercially available reagents were used without further purification. All reactions were monitored by TLC with precoated aluminum foil sheets $(0.20 \mathrm{~mm}$ with fluorescent indicator $\mathrm{UV}_{254}$ ). Compounds were visualized with UV light at 254 and $365 \mathrm{~nm}$. Melting points were measured by differential scanning calorimetry (DSC). Infrared (IR) spectra were recorded within $\mathrm{KBr} .{ }^{1} \mathrm{H} \mathrm{NMR}$ and ${ }^{13} \mathrm{C} \mathrm{NMR}$ in $\mathrm{CDCl}_{3}$ were recorded with a spectrometer at 400 and $100 \mathrm{MHz}$, respectively. Low- and high-resolution mass spectra were recorded in the FAB mode.

4.2. Synthesis. (a) Synthesis of 5-Bromo-2-phenylethynylpyrimidine (2). ${ }^{17 a}$ A mixture of phenylacetylene $(0.13 \mathrm{~mL}$, 
$1.2 \mathrm{mmol})$, 5-bromo-2-iodopyrimidine (1) $(285 \mathrm{mg}, 1.0 \mathrm{mmol}$ ), $\mathrm{CuI}$ (9.5 mg, $0.05 \mathrm{mmol}), \mathrm{Pd}\left(\mathrm{PPh}_{3}\right)_{4}(57.8 \mathrm{mg}, 0.05 \mathrm{mmol})$, and diisopropylamine $(0.28 \mathrm{~mL}, 2.0 \mathrm{mmol})$ in dry THF $(10 \mathrm{~mL})$ was placed in a sealed two-neck flask under argon. The mixture was stirred at room temperature for $24 \mathrm{~h}$. The resulting reaction mixture was filtered through a pad of silica gel (or $\left.\mathrm{Al}_{2} \mathrm{O}_{3}\right)$ and washed with $\mathrm{Et}_{2} \mathrm{O}(2 \times 15 \mathrm{~mL})$. The filtrate was concentrated under reduced pressure. The resultant crude product was purified by chromatography on silica gel, eluting with EtOAc/hexane = 1/9 to afford the cross-coupling product as a white solid $(210 \mathrm{mg}, 80 \%) .{ }^{1} \mathrm{H} \mathrm{NMR}\left(\mathrm{CDCl}_{3}, 400 \mathrm{MHz}\right) \delta$ $7.37(\mathrm{~m}, 3 \mathrm{H}), 7.65(\mathrm{~d}, 2 \mathrm{H}, J=8.1 \mathrm{~Hz}), 8.79(\mathrm{~s}, 2 \mathrm{H}) ;{ }^{13} \mathrm{C} \mathrm{NMR}$ $\left(\mathrm{CDCl}_{3}, 400 \mathrm{MHz}\right) \delta 87.1,89.4,118.9,121.0,128.4,129.9$, 132.6, 151.0, 158.0; $\mathrm{MS}\left(\mathrm{M}+\mathrm{H}^{+}, \mathrm{m} / z, \mathrm{FAB}^{+}\right) 258.9$ (70); HRMS $\left(\mathrm{M}+\mathrm{H}^{+}, \mathrm{FAB}^{+}\right)$calcd for $\mathrm{C}_{12} \mathrm{H}_{8}{ }^{79} \mathrm{BrN}_{2} 258.9871$, found 258.9868, and for $\mathrm{C}_{12} \mathrm{H}_{8}{ }^{81} \mathrm{BrN}_{2} 260.9850$, found 260.9853 .

(b) Synthesis of 2,5-Bis(phenylethynyl)pyrimidine (3). A mixture of phenylacetylene $(0.13 \mathrm{~mL}, 1.2 \mathrm{mmol}), 5$-bromo2-phenylethynylpyrimidine $(259 \mathrm{mg}, 1.0 \mathrm{mmol}), \mathrm{CuI}(9.5 \mathrm{mg}$, $0.05 \mathrm{mmol}), \mathrm{Pd}\left(\mathrm{PPh}_{3}\right)_{4}(57.8 \mathrm{mg}, 0.05 \mathrm{mmol})$, and diisopropylamine $(0.28 \mathrm{~mL}, 2.0 \mathrm{mmol})$ in dry THF $(10 \mathrm{~mL})$ was placed in a sealed two-neck flask under Argon. The mixture was heated and stirred at $80^{\circ} \mathrm{C}$ for $24 \mathrm{~h}$ and then cooled to room temperature. The solution was filtered through a pad of silica gel, and the filtrate was concentrated under reduced pressure. The residue was chromatographed on silica gel, eluting with EtOAc/hexane $=1 / 7$ to give 2,5 -bis( phenylethynyl)pyrimidine (238 mg, 85\%). Mp $181.1{ }^{\circ} \mathrm{C}$ (DSC analysis); IR (neat) $v 3052$, 2227, 2214, 2200, 1494, and $1428 \mathrm{~cm}^{-1}$; ${ }^{1} \mathrm{H} \mathrm{NMR}\left(\mathrm{CDCl}_{3}, 400\right.$ $\mathrm{MHz}) \delta 7.40(\mathrm{~m}, 6 \mathrm{H}), 7.56(\mathrm{~d}, 2 \mathrm{H}, J=7.6 \mathrm{~Hz}), 7.68(\mathrm{dd}, 2 \mathrm{H}, J$ $=1.6,7.6 \mathrm{~Hz}), 8.85(\mathrm{~s}, 2 \mathrm{H}) ;{ }^{13} \mathrm{C} \mathrm{NMR}\left(\mathrm{CDCl}_{3}, 400 \mathrm{MHz}\right) \delta 82.6$, 88.0, 90.0, 97.8, 117.9, 121.1, 121.7, 128.4, 128.5, 129.4, 131.7, 132.6, 150.6, 158.9; $\mathrm{MS}\left(\mathrm{m} / z, \mathrm{FAB}^{+}\right) 281(15), 147$ (100), 74 (55); HRMS $\left(\mathrm{M}^{+}, \mathrm{FAB}^{+}\right)$calcd $\mathrm{C}_{20} \mathrm{H}_{12} \mathrm{~N}_{2}$ 280.1000, found 280.1007. Anal. Calcd.for $\mathrm{C}_{20} \mathrm{H}_{12} \mathrm{~N}_{2}$ : C, 85.69; H, 4.31; N, 9.99. Found: C, 85.31; H, 4.64; N, 9.58.

(c) Synthesis of 2-Phenylethynyl-5-(4-trimethylsilylethynylphenylethynyl)pyrimidine (4). A mixture of 4-(trimethylsilylethynyl)phenylacetylene $(238 \mathrm{mg}, 1.2 \mathrm{mmol}), 5$-bromo-2-phenylethynylpyrimidine (2) (259 mg, $1.0 \mathrm{mmol}), \mathrm{CuI}(9.5$ $\mathrm{mg}, 0.05 \mathrm{mmol}), \mathrm{Pd}\left(\mathrm{PPh}_{3}\right)_{4}(57.8 \mathrm{mg}, 0.05 \mathrm{mmol})$, and diisopropylamine $(0.28 \mathrm{~mL}, 2.0 \mathrm{mmol})$ in dry THF $(10 \mathrm{~mL})$ was placed in a sealed two-neck flask under argon. The mixture was stirred at $80{ }^{\circ} \mathrm{C}$ for $24 \mathrm{~h}$. Chromatography on silica gel and eluting with EtOAc/hexane = 1/7 afforded $4(300 \mathrm{mg}, 80 \%)$. $\mathrm{Mp} 208.2{ }^{\circ} \mathrm{C}$ (DSC analysis); IR (neat) $v 2960,2225,2157$, $1500,1495,1427,1421 \mathrm{~cm}^{-1} ;{ }^{1} \mathrm{H}$ NMR $\left(\mathrm{CDCl}_{3}, 400 \mathrm{MHz}\right) \delta$ $0.25(\mathrm{~s}, 9 \mathrm{H}), 7.40(\mathrm{~m}, 3 \mathrm{H}), 7.48(\mathrm{~m}, 4 \mathrm{H}), 7.67(\mathrm{dd}, 2 \mathrm{H}, J=1.7$, $8.0 \mathrm{~Hz}), 8.84(\mathrm{~s}, 2 \mathrm{H}) ;{ }^{13} \mathrm{C} \mathrm{NMR}\left(\mathrm{CDCl}_{3}, 400 \mathrm{MHz}\right) \delta 84.3,87.9$, 90.2, 97.2, 97.3 104.1, 117.6, 121.1, 121.5, 124.2, 128.4, 129.9, 131.5, 132.0, 132.6, 150.7, 158.8; $\mathrm{MS}\left(\mathrm{m} / z, \mathrm{FAB}^{+}\right) 377(25), 136$ (60); HRMS $\left(\mathrm{M}^{+}, \mathrm{FAB}^{+}\right.$) calcd for $\mathrm{C}_{25} \mathrm{H}_{20} \mathrm{~N}_{2} \mathrm{Si}$ 376.1396, found 376.1396. Anal. Calcd for $\mathrm{C}_{25} \mathrm{H}_{20} \mathrm{~N}_{2} \mathrm{Si}$ : C, 79.75; H, 5.35; N, 7.44. Found: C, $79.54 \mathrm{H}, 5.35 \mathrm{~N}, 7.39$.

(d) Synthesis of 5-(4-Ethynylphenylethynyl)-2-phenylethynylpyrimidine (5). 2-Phenylethynyl-5-(4-trimethylsilylethynylphenylethynyl)pyrimidine (4) $(377 \mathrm{mg}, 1.0 \mathrm{mmol})$ was dissolved in THF $(10 \mathrm{~mL})$, and a solution of potassium carbonate $(70 \mathrm{mg}, 0.5 \mathrm{mmol})$ dissolved in methanol $(5 \mathrm{~mL})$ was added. After the mixture was stirred for $1 \mathrm{~h}$ at ambient temperature, the residue was concentrated and purified by chromatography on silica gel, eluting with $\mathrm{CH}_{2} \mathrm{Cl}_{2} /$ hexane $=$ $1 / 2$ to give the product 5-(4-ethynyl-phenylethynyl)-2-phenylethynylpyrimidine $(230 \mathrm{mg}, 75 \%)$. The analytically pure product was recrystallized from $\mathrm{CH}_{2} \mathrm{Cl}_{2}$ and hexane. $\mathrm{Mp} 210.8$ ${ }^{\circ} \mathrm{C}$ (DSC analysis); IR (neat) $v 3283,2230,1496,1427 \mathrm{~cm}^{-1}$; ${ }^{1} \mathrm{H} \mathrm{NMR}\left(\mathrm{CDCl}_{3}, 400 \mathrm{MHz}\right) \delta 3.2(\mathrm{~s}, 1 \mathrm{H}), 7.38(\mathrm{~m}, 3 \mathrm{H}), 7.49(\mathrm{~s}$, $4 \mathrm{H}), 7.66(\mathrm{~d}, 2 \mathrm{H}, J=6.4 \mathrm{~Hz}), 8.83(\mathrm{~s}, 2 \mathrm{H}) ;{ }^{13} \mathrm{C} \mathrm{NMR}$ $\left(\mathrm{CDCl}_{3}, 400 \mathrm{MHz}\right) \delta 79.6,82.8,84.4,87.9,90.2,97.0,117.6$, $121.1,122.0,123.2,128.5,129.9,131.6,132.2,132.6,150.8$, 158.9; $\mathrm{MS}\left(\mathrm{m} / z, \mathrm{FAB}^{+}\right) 304(3), 136$ (60); HRMS $\left(\mathrm{M}^{+}, \mathrm{FAB}^{+}\right)$ calcd for $\mathrm{C}_{22} \mathrm{H}_{12} \mathrm{~N}_{2}$ 304.1000, found 304.1007. Anal. Calcd for $\mathrm{C}_{22} \mathrm{H}_{12} \mathrm{~N}_{2}$ : C, 86.82; H, 3.97; N, 9.20. Found: C, 86.79; H, 4.05; N, 9.17 .

4.3. Photophysical Measurements. Steady-state absorption and emission spectra were recorded with a corrected excitation light source. In addition, the wavelength-dependent characteristics of the monochromator and photomultiplier have been calibrated by recording the scattered light spectrum of the corrected excitation light from a diffused cell in the 220$700 \mathrm{~nm}$ ranges. To obtain the precise extinction coefficient five different concentrations ranging from $5 \times 10^{-5}$ to $5 \times 10^{-7} \mathrm{M}$ were performed. Quinine Sulfate in $1 \mathrm{~N} \mathrm{H}_{2} \mathrm{SO}_{4}$ aqueous solution was used as a reference, assuming a yield of 0.57 with a 325-nm excitation, to determine the fluorescence quantum yields of the studied compounds in solution. Lifetime studies were performed by a photon-counting system with a hydrogenfilled/or a nitrogen lamp as the excitation source. Data were analyzed by using the nonlinear least-squares procedure in combination with an iterative convolution method. The emission decays were analyzed by the sum of exponential functions, which allows partial removal of the instrument time broadening and consequently renders a temporal resolution of $\sim 200$ ps.

A configuration of front-face excitation was used to measure the emission of the solid crystal. The solid crystal was fixed by assembling two edge-polished quartz plates with various Teflon spacers. A combination of appropriate filters was used to avoid the interference from the scattering light. An integrating sphere was applied to measure the quantum yield in the solid state, in which the solid sample film was prepared via either the spin coating or the vapor deposition method and was excited by a 325-nm $\mathrm{He}-\mathrm{Cd}$ laser line. The resulting luminescence was acquired by an intensified charge-coupled detector for subsequent quantum yield analyses.

Acknowledgment. We thank the National Science Council and Ministry of Education for financial support. The authors thank Prof. Hsiu-Fu Hsu for his constructive suggestions.

Supporting Information Available: Summarized crystal data and crystallographic data (CIF) for 3, 4, and 5. This material is available free of charge via the Internet at http://pubs.acs.org.

JO048914H 